<smiles>CCCCc1cccc(Br)c1I</smiles>

(I)

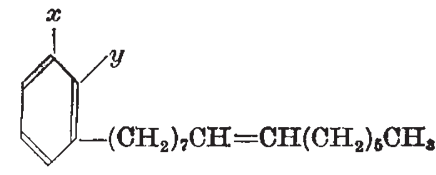

(II)

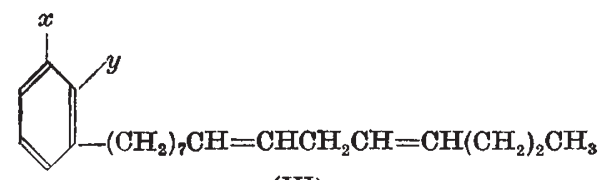

(III)

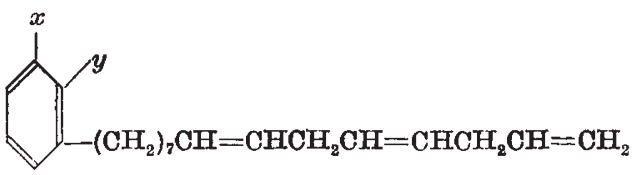

(IV)

Components of poison fvy urushiol $(x=y=\mathrm{OH})$

components of poison ivy urushiol. The structures of the pure components of cardanol, therefore, can be represented as I, II, III and IV, respectively, where $x=\mathrm{OH}$ and $y=\mathrm{H}$.

Anacardic acid, the alkenyl salicylic acid component of cashew nut shell liquid, also absorbs two moles of hydrogen and is hetero-olefinic. On reduction it is converted into 2-carboxy-3-pentadecylphenol. Since anacardic acid gives cardanol on smooth decarboxylation, it seems probable that the heteroolefinic character of anacardic acid can be explained in terms of olefinic components corresponding in structures to those found in cardanol (I, II, III and IV ; $x=\mathrm{OH}, y=\mathrm{COOH})$.

Cardol, the toxic resorcinol component of cashew nut shell liquid, usually absorbs somewhat more than two molar equivalents of hydrogen and is converted into 1,3-dihydroxy-5-pentadecylbenzene. It was found to be composed mainly of a diolefin and a triolefin having alkenyl side-chains identical with those shown above.

No component having more than three double bonds could be detected in any of the three alkenyl phenols investigated.

A detailed account of this work will be reported elsewhere. We are indebted to the Lederle Laboratories Division of the American Cyanamid Company for a grant supporting this investigation. An extract of poison ivy was also supplied by the Lederle Laboratories. The cashew nut shell liquid was kindly supplied by the Irvington Varnish and Insulator Company.

W. F. Symes

C. R. DAwson

Department of Chemistry, Columbia University, New York. Nov. 18.

' (a) Majima, R., Ber., 55 B, 172 (1922). (b) Hill, G. A., Mattacotti, V., nd Graham, W.D.,J.Amer. Chem. Soc. 56, 2736(1934). (c) Backe H.J., and Haack, N. H., Rec. Trav. Chem., 60, 661 (i941).

${ }^{2}$ Kefl, H., Wasserman, D., and Dawson, C. R.. J.. Exp. Med.; 80, 275

"Harvey, M. T., and Caplan. S., Indust. and Eng. Chem., 32, 130 $(1940)$.

- Sunthankar, S. V., and Dawson, C. R. (unpublished work).

'Sletzinger, M., and Dawson, C. R., J. Org. Chem., 14, 670 (1949). Izzo, P. T.; and Dawson, C. R., J. Org. Chem., 14, 1039 (1949);

-Mason, H. S., and Schwartz, L.. J. Amer. Chem. Soc., 64, 3058 (1942).

\section{Specific Volume of Cellulose in Aqueous Solutions of Inorganic Salts}

The specific volume of cellulose (sheet viscose) in aqueous solutions of ammonium, sodium and potassium chlorides, at $25^{\circ} \mathrm{C}$., has been measured, using a 'hydrostatic balance', for the whole of the solubility range of the salt.

The curve obtained in the plot of specific volume against concentration passes through a maximum in each case. The concentration of the external solution at the maximum specific volume for each salt is:

\begin{tabular}{lc}
\multicolumn{1}{c}{ Salt } & Concentration (wt. per cent) \\
Ammonium chloride & $14 \cdot 3$ \\
Sodium chloride & $18 \cdot 0$ \\
Potassium chloride & $16 \cdot 0$
\end{tabular}

Calculation of the ratio of gram molecules of water per gram cation at this concentration, assuming equal hydration of anion and cation in all cases, gives the following values:

$$
\begin{array}{lr}
\text { Ion } & \text { Ratio } \\
\mathrm{NH}_{4}^{+} & 8 \cdot 9 \\
\mathrm{Na}^{+} & 7 \cdot 5 \\
\mathrm{~K}^{+} & 11 \cdot 6
\end{array}
$$

From the effective radius of the ion ${ }^{1}$ and of the water molecule, the number of water molecules which can be arranged around each ion, from purely geometrical considerations, may be calculated:

\begin{tabular}{lcc}
\multicolumn{1}{c}{ Ion } & Radius (A.) & $\begin{array}{c}\text { 'Geometrical' number } \\
\text { of water molecules }\end{array}$ \\
$\mathrm{NH}_{+}^{+}$ & 1.42 & $12 \cdot 0$ \\
$\mathrm{Na}^{+}$ & 0.95 & 7.5 \\
$\mathrm{~K}^{+}$ & 1.33 & $12 \cdot 0$ \\
$\mathrm{H}_{2} \mathrm{O}$ mol. & 1.38 & $12 \cdot 0$
\end{tabular}

The following suggestion is offered in explanation of the specific volume curve.

There is evidence ${ }^{2}$ for believing that, in the initial stages of water adsorption by cellulose, the water is under a compressive force, causing it to have a density greater than ordinary liquid water.

Addition of a salt provides polar centres which disorganize the water atmosphere, and has a docompressing effect on the adsorbed water layer. The specific volume of the cellulose therefore increases with increasing salt concentration, until the activity of the water in the system is so reduced that it is unable to satisfy the hydration requirements of the ions. Further addition of salt then results in direct linkage of the salt ions with the cellulose, and the specific volume decreases once more.

S. M. NEALE

G. R. WILLIAMSON

College of Technology,

Manchester 1.

Dec. 2.

${ }^{1}$ Goldschmidt, Trans. Farad. Soc., 25, 253 (1929).

${ }^{2}$ Davidson, $J$ Text. Inst. 18, T175 (1927). Filby and Mars, Canad. $J$. Res., $\dot{y}, 162$ (1932). Stamm and Seborg, J. Phys. Chem., 39.

\section{Absorption Spectra of the Ethyl Chlorophyllides}

The spectra of the ethyl chlorophyllides, the crystalline derivatives of chlorophyll by replacement of the phytyl by the ethyl radical, are of interest as these compounds are valuable as actinometry standards in the study of the efficiency of photosynthesis. No report seems to have been made of 